\title{
Política monetária e senhoriagem: depósitos compulsórios na economia brasileira recente
}

\author{
Roberto Meurer*
}

\begin{abstract}
RESUMO - Neste artigo se analisa a utilização dos depósitos compulsórios sobre depósitos à vista como medida de política monetária no período recente no Brasil. Os depósitos compulsórios ainda são elevados no Brasil, gerando receita fiscal através do ganho de senhoriagem. Um depósito compulsório remunerado sobre os depósitos à vista foi introduzido em 2002, e mantido desde lá. No contexto da recente crise financeira internacional os depósitos compulsórios, remunerados e não remunerados foram reduzidos, com o objetivo de facilitar a concessão de crédito por parte dos bancos.
\end{abstract}

Palavras-chave: Política monetária. Depósito compulsório. Senhoriagem.

Neste artigo são discutidos dois aspectos da condução da política monetária no Brasil em relação aos depósitos compulsórios. Primeiramente, é discutida a instituição de um depósito compulsório remunerado sobre depósitos à vista, em 2002 e, posteriormente, a redução dos compulsórios no contexto da recente crise financeira no sistema financeiro internacional. No caso dos depósitos compulsórios remunerados o interesse é sobre o custo dessa medida, enquanto no segundo se discute a eficácia dessas medidas em um cenário de aversão a risco e redução do crédito por parte do sistema financeiro. Estes temas são contextualizados na condução da política monetária brasileira recente.

A tradicional classificação dos instrumentos de política monetária em operações de mercado aberto, redesconto e depósitos compulsórios está sendo menos enfatizada na literatura recente, por causa da constatação de que os bancos centrais têm condições de definir a taxa de juros ou o agregado monetário que tenha como meta operacional para a política monetária. Esta meta operacional, por conseqüência, passa a ser considerada o instrumento de política monetária. Para atingir o objetivo quantitativo para este instrumento, a taxa de juros ou o valor da base monetária continuam sendo utilizadas como as tradicionais medidas de política monetária. Por conseqüência, também continuam ocorrendo os efeitos dessas medidas, que influenciam outras variáveis, incluindo efeitos diretos sobre as finanças públicas.

Há uma forte inter-relação entre o comportamento da política monetária, teoricamente a cargo do banco central, e a política fiscal, executada pelo tesouro. As decisões

\footnotetext{
* Doutor em Engenharia de Produção pela Universidade Federal de Santa Catarina. Atualmente é Professor Adjunto do Departamento de Economia daquela instituição. Endereço Eletrônico: rmeurer@pq.cnpq.br.
} 
de política monetária, sobre juros, por exemplo, influenciam os custos da dívida pública, através de títulos indexados à taxa de juros ou através da estrutura a termo da taxa de juros. Por outro lado, o tesouro, ao efetuar os pagamentos e arrecadações, influencia o volume de dinheiro em circulação. Para o setor privado não faz diferença se as decisões são tomadas por uma autoridade ou outra, interessando o resultado final. Da mesma forma, não interessam para os tomadores de decisão fora do setor público as relações e os ajustes contábeis entre os diferentes níveis e esferas de governo, mas o seu efeito líquido sobre a economia. No caso brasileiro, por exemplo, não faz diferença para o restante da economia a existência de títulos do Tesouro Nacional na Carteira do Banco Central ou se a intervenção no mercado cambial foi efetuada pelo Tesouro Nacional ou pelo Banco Central. Por outro lado, faz diferença se os gastos do governo foram esterilizados ou não através de operações com títulos públicos ou se as intervenções no mercado cambial são compensadas por superávit ou déficit fiscal.

As medidas de política monetária têm relação com a política fiscal também no caso da execução da política monetária através de depósitos compulsórios. Alterações de base monetária geram senhoriagem - receita, em caso de expansão, e despesa, em caso de contração. A receita ou despesa é igual à variação do estoque da base monetária. A base monetária é definida, com pequenas variações decorrentes de especificidades do sistema financeiro e de pagamentos dos países, como a soma do papel moeda emitido com as reservas bancárias mantidas junto aos bancos centrais. Usualmente as reservas sobre depósitos à vista não têm remuneração. Recentemente, entretanto, os Estados Unidos, no contexto da crise financeira que eclodiu em 2007 e se aprofundou no segundo semestre de 2008, instituiu remuneração sobre as reservas, com o objetivo de estimular os bancos a aumentarem o seu nível de reservas, ou seja, reduzir o risco das instituições financeiras.

Tradicionalmente, no Brasil também não há remuneração sobre as reservas, mas em 2002 foi criada uma "exigibilidade adicional" de compulsório que é remunerada pelo Banco Central. O contexto desta medida foi a implementação de uma política monetária contracionista, quando as taxas de inflação estavam se elevando, pressionadas pela depreciação da moeda brasileira no período anterior à eleição presidencial. Com este depósito compulsório remunerado os bancos teriam menor interesse em efetuar empréstimos, o que contribuiria para reduzir a demanda e a inflação.

O nível ótimo de reservas mantido por um banco é teoricamente determinado pela igualdade do custo marginal de falta com o custo de oportunidade da remuneração perdida sobre as reservas. O custo de falta é dado pelas conseqüências de a instituição não dispor das 
reservas em caso de necessidade. No caso do custo de oportunidade, mesmo que haja remuneração sobre os depósitos compulsórios, existirá o custo de oportunidade de aplicações com maior rentabilidade do que a do compulsório.

Não havendo remuneração do compulsório ou existindo alternativas melhores de aplicação dos recursos, as instituições financeiras procurarão manter o menor volume possível de reservas. Este é dado pela exigência mínima de saldo na conta de reservas, calculado a partir dos saldos médios das contas sobre as quais incide o depósito compulsório. No caso brasileiro, além dos depósitos compulsórios sobre recursos à vista, também há depósitos compulsórios sobre depósitos de caderneta de poupança, depósitos a prazo e outras operações de menores volumes. Como os recursos que não são à vista são remunerados pelos bancos, o Banco Central também os remunera.

A origem dos depósitos compulsórios está na redução, pela autoridade monetária, da capacidade de multiplicação da moeda por parte dos bancos comerciais. Em períodos mais recentes, entretanto, mudanças na regulação do sistema financeiro levaram à redução do nível de exigência de depósito compulsório ao redor do mundo. Isto é possível porque há outras maneiras de evitar a criação excessiva de moeda, como os requerimentos mínimos de capital associados ao nível de ativos dos bancos, como estabelecido no acordo da Basiléia.

As diferentes formas de operacionalizar a política monetária podem ser utilizadas para implementar uma política expansionista ou contracionista. A diferença entre elas é que as operações de redesconto e com títulos públicos afetam diretamente o volume da base monetária, enquanto uma alteração no depósito compulsório não afeta diretamente a base monetária, mas sim o multiplicador monetário, fazendo com que, para um mesmo estoque de base monetária possa existir um maior volume de meios de pagamento, através da criação de depósitos a vista pelos bancos comerciais.

O interesse em se manter depósitos compulsórios, mesmo com outras alternativas de controle sobre o sistema financeiro, pode ser explicado pela obtenção de receita de senhoriagem. O aumento da demanda por papel-moeda por parte do público, se atendida, necessariamente implica geração de receitas de senhoriagem para a autoridade monetária, dado o monopólio de emissão. No caso de aumento da demanda por depósitos à vista, caso não existissem depósitos compulsórios, o atendimento a essa maior demanda se daria pelos bancos detentores de depósitos à vista. Com compulsórios, a possibilidade de emissão adicional de passivos pelos bancos comerciais é parcialmente dividida com a autoridade monetária que, com isso, obtém receitas de senhoriagem. No limite, com um recolhimento 
compulsório de 100\%, os bancos não criariam depósitos à vista e o aumento da demanda por depósitos à vista seria totalmente apropriado pelo banco central. Esta situação é próxima da ocorrida no início do Plano Real, em que a alíquota de compulsório foi de 100\% sobre os acréscimos de saldos.

As receitas de senhoriagem são mais elevadas em períodos de inflação elevada. Entretanto, como pode ser observado no Gráfico 1, as receitas de senhoriagem obtidas pelo governo brasileiro ao longo do tempo são relevantes mesmo nos períodos mais recentes de inflação controlada.

\section{GRÁFICO 1 - RECEITA DE SENHORIAGEM COMO PROPORÇÃO DO PIB}

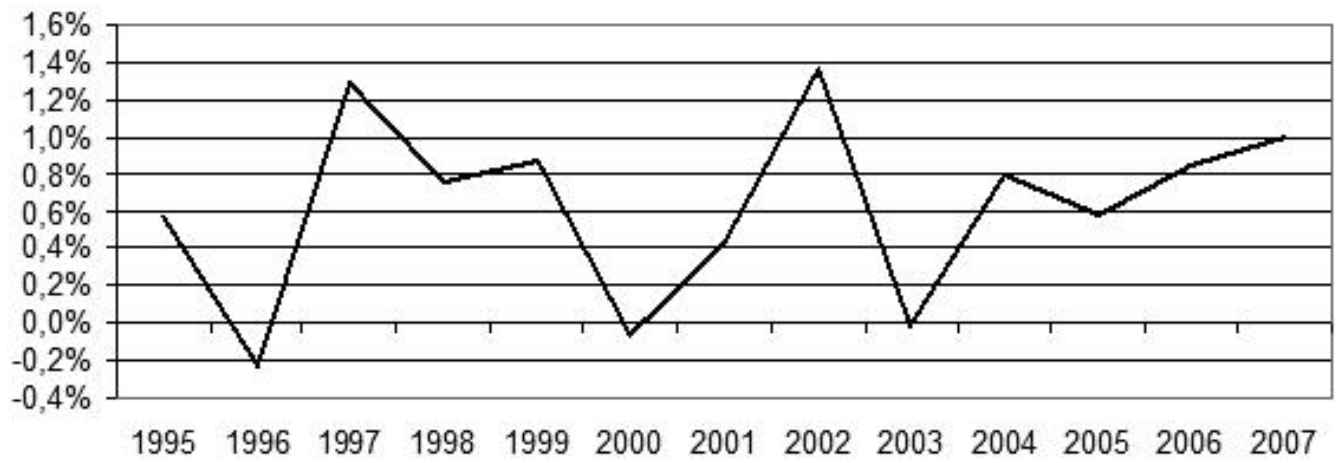

FONTE: Calculado a partir de dados do Banco Central do Brasil e Instituto Brasileiro de Geografia e Estatística. A senhoriagem foi obtida pela divisão entre a variação nominal da base monétaria da base monetária no ano pelo PIB nominal do ano.

Como as diferentes operacionalizações da política monetária têm efeitos expansionistas e contracionistas é necessário que haja coerência entre elas na condução da política monetária. No gráfico 2 pode-se observar que, ao longo do período de agosto de 1994 a outubro de 2008, esta coerência existiu: as alíquotas dos depósitos compulsórios acompanharam os movimentos das taxas de juros, ou seja, os compulsórios foram reduzidos em períodos de redução dos juros ou, pelo menos, não tiveram movimento em sentidos opostos.

A “exigibilidade adicional” remunerada sobre os depósitos à vista, introduzida em 2002, quando uma política monetária contracionista estava em curso, não foi revertida quando a política passou a ser expansionista em 2003, e mantida nos ciclos contracionistas e expansionistas posteriores, até a sua eliminação em outubro de 2008. Uma questão importante é a necessidade de manutenção dessa remuneração adicional sobre recursos captados pelos bancos com custo zero. Caso o interesse em uma política monetária expansionista incluísse a utilização do canal do crédito, esta remuneração das reservas poderia ser eliminada, gerando uma tendência de expansão do crédito e amplificação dos efeitos da 
política monetária. No caso de política contracionista, a remuneração sobre esse recolhimento adicional poderia não ser necessária porque o efeito contracionista seria obtido com o simples aumento da alíquota normal do compulsório, sem a geração do custo fiscal da remuneração.

Os custos gerados pela remuneração desse compulsório sobre os depósitos à vista não é desprezível, chegando, entre 2003 e 2007, a valores anuais próximos a R \$ 1 bilhão.

GRÁFICO 2 - DEPÓSITO COMPULSÓRIO E TAXA DE JUROS

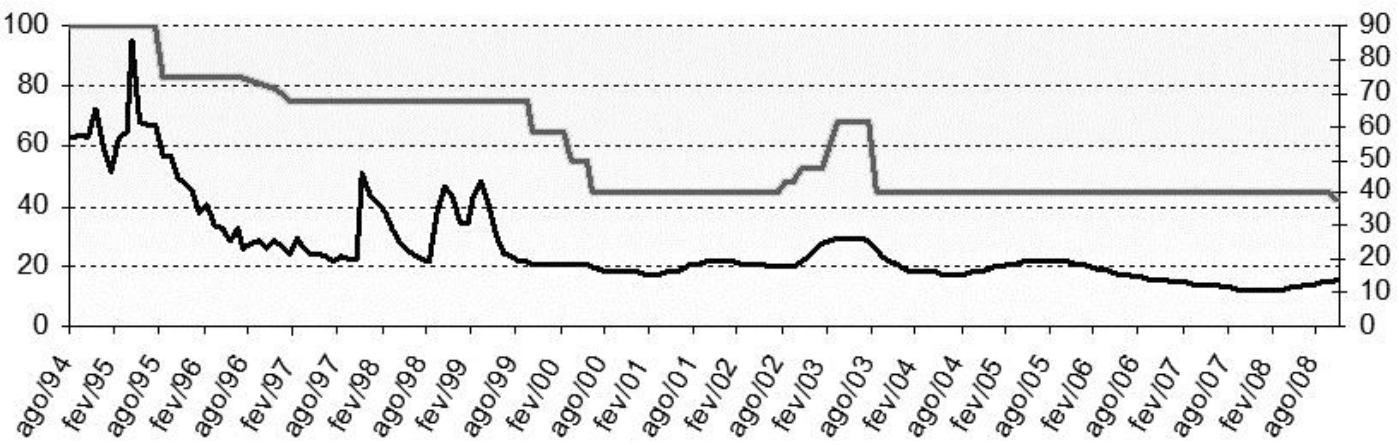

—Dep.Com pulsório —SELIC

FONTE: Normativos do Banco Central do Brasil e séries temporais do Banco Central do Brasil.

NOTA: Alíquota do depósito compulsório no eixo equerdo, e taxa SELIC efetiva no eixo direito.

O aprofundamento da crise financeira internacional a partir de setembro de 2008 levou o Banco Central do Brasil a adotar uma série de medidas para assegurar a liquidez nos mercados financeiros e a continuidade da concessão de crédito por parte das instituições. Coerentemente, os juros básicos da economia não foram aumentados na reunião do Copom no final de outubro. Se fossem, mantida constante a demanda por moeda, a liquidez adicional gerada teria de ser recolhida através de operações com títulos públicos.

As medidas visaram induzir a continuidade da concessão de empréstimos para tomadores finais e no mercado interfinanceiro. A preocupação do Banco Central com o aumento da aversão ao risco por parte dos bancos em face das incertezas sobre o cenário da economia brasileira e mundial levou à tomada das medidas que visaram criar estímulos ao financiamento dos tomadores finais de recursos e evitar o "empoçamento" da liquidez entre instituições financeiras. Isto incluiu a redução das alíquotas de depósitos compulsórios. Uma questão a ser verificada é se estas medidas de expansão monetária fizeram o seu papel. Caso não esteja ocorrendo aumento do crédito por parte do sistema financeiro, o Banco Central pode estar recolhendo a liquidez gerada através de operações compromissadas.

Caso os bancos não estejam, no agregado, aumentando as suas operações de crédito, os recursos liberados poderiam ter dois destinos. Caso permaneçam como reservas bancárias no Banco Central, por estarem as reservas acima do mínimo requerido, não teriam 
remuneração. A ocorrência desta hipótese significaria que os bancos não estariam reagindo ao incentivo da autoridade monetária, cujo objetivo era aumentar a oferta de crédito (ou conter a sua retração). Isto significa que, na avaliação dos bancos, a receita obtida com os empréstimos não compensaria o risco de inadimplência. Em outras palavras, o custo de oportunidade dos juros perdidos é inferior à possível perda ao efetuar o empréstimo. Esta possibilidade estaria ocorrendo no caso de uma redução do multiplicador monetário em decorrência do aumento da relação entre reservas e depósitos por parte dos bancos.

A segunda possibilidade é de o excesso de liquidez, em decorrência do fato de o aumento das reservas livres não ter sido repassado pelo sistema financeiro, ser recolhido pelo Banco Central através de operações compromissadas com títulos públicos, o tradicional instrumento utilizado para a sintonia fina da política monetária. Esta hipótese também implica que o objetivo das medidas de liberação de compulsórios das diferentes formas não atingiu seu objetivo. Esta possibilidade ocorreria no caso de ocorrer uma redução da exigência de reservas sem que o multiplicador monetário se alterasse. A utilização das operações compromissadas para o ajuste da oferta monetária de curto prazo é comum em um contexto de meta operacional de taxa de juros de curtíssimo prazo. Estas operações são geralmente efetuadas com taxas punitivas, em que os empréstimos concedidos pelo Banco Central têm taxa superior à taxa dos negócios entre as instituições financeiras, e os recursos tomados pelo Banco Central têm remuneração inferior, o que significa um incentivo para que o mercado resolva as suas necessidades de liquidez por conta própria.

Caso o Banco Central esteja recolhendo o excesso de reservas do mercado, o custo de oportunidade dos bancos é fortemente reduzido, por representar a ocorrência de uma remuneração que de outra forma não ocorreria. Por outro lado, a ação do Banco Central poderia ser considerada contraditória, ao liberar recursos para uma finalidade e tornar a remunerá-los quando não cumprem essa finalidade.

Isto significaria a necessidade de aumentar a punição em caso de os recursos voltarem ao Banco Central, ou seja, reduzir a remuneração desses recursos. Esta possibilidade é factível de ser implementada porque, como os bancos não estariam tendo interesse em repassar os recursos no mercado, o único tomador residual de recursos seria o Banco Central que, desta forma, seria um monopsonista. Caso o Banco Central aumente a punição pela retenção das reservas, reduzindo a remuneração das reservas recolhidas nas operações compromissadas, é possível que passe a existir interesse das instituições financeiras em repassar os recursos. 
Do ponto de vista estritamente financeiro, para as contas públicas, a remuneração das reservas é contraproducente quando não é atingido o outro objetivo da política, o de aumentar os empréstimos do sistema financeiro, porque passa a existir um custo com juros sobre as reservas recolhidas, que estariam ociosas e sem remuneração caso isso não ocorresse.

Percebe-se pelo Gráfico 3 que ao longo do mês de outubro houve aumento do estoque de operações de mercado aberto pelo Banco Central, especialmente na primeira quinzena, e tendência de queda a partir da segunda quinzena.

GRÁFICO 3 - OPERAÇÕES DE MERCADO ABERTO DO BANCO CENTRAL.

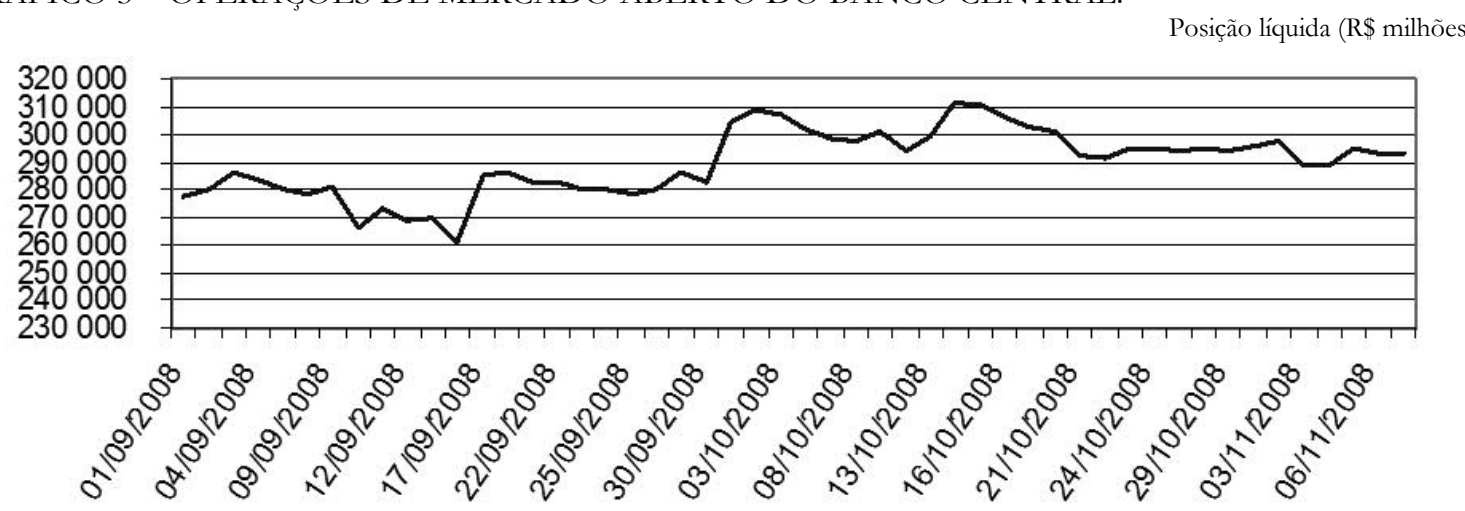

FONTE: Banco Central do Brasil

Verificando o comportamento do total de depósitos compulsórios, remunerados e não remunerados, há redução ao longo do mês de outubro e início de novembro. No final de agosto, o total de depósitos compulsórios, remunerados e não-remunerados, é de $\mathrm{R} \$ 259,4$ bilhões; em setembro, R\$ 272 bilhões e, em outubro, $\mathrm{R} \$ 219,7$ bilhões, valor que é aproximadamente mantido no início de novembro.

Por outro lado, o nível de reservas bancárias não oscilou significativamente, mostrando que não há relevante alteração de comportamento do Banco Central ou dos bancos quanto à gestão das reservas bancárias.

Combinando a análise do comportamento destes diferentes agregados, existe a possibilidade de que as medidas de ampliação de liquidez estejam funcionando, o que teria de ser confirmado pelos dados das operações de crédito. Uma outra alternativa, que tem respaldo no comportamento dos fatores condicionantes da base monetária, é de que a liquidez gerada tenha sido direcionada à aquisição de moeda estrangeira, o que certamente não era o objetivo do Banco Central, tanto em termos de crédito doméstico quanto de controle da inflação.

A dificuldade do governo brasileiro em gerar um superávit fiscal suficientemente elevado para compensar a liquidez externa gerada pelo superávit em transações correntes e 
entrada de capitais, especialmente a partir de 2004, reduz atualmente a flexibilidade da condução da política monetária. Um superávit fiscal mais elevado nos últimos anos teria permitido uma maior intervenção do Banco Central no mercado cambial, o que teria evitado a apreciação da moeda brasileira até os níveis observados. Com isso, os superávits em conta corrente não teriam se transformado em déficits em uma velocidade tão rápida a partir do último trimestre de 2007. Menores déficits em transações correntes, ou a manutenção dos superávits, significaria menor dependência de financiamento externo.

Para a política monetária, o fato de o superávit fiscal não ser suficiente para anular a entrada de moeda estrangeira significa que ocorrerá pressão para apreciação da moeda brasileira, e a intervenção no mercado cambial através da compra de divisas tem de ser esterilizada através de operações com títulos públicos, dada a existência de uma meta operacional de taxa de juros para a política monetária. Com a reversão do fluxo de capitais que ocorreu com a crise nos mercados financeiros mundiais, a saída de recursos estrangeiros aliada à existência de déficit em transações correntes limitou a capacidade de intervenção do governo no mercado de câmbio, embora esta tenha sido forte ao longo dos últimos meses.

Adicionalmente, um menor estoque de dívida pública permitiria maior agressividade na redução da taxa de juros, pela menor pressão advinda do câmbio sobre os preços.

A condução da política monetária no Brasil, como se pode perceber, permanece tendo fortes ligações com a política fiscal, como a criação de receitas de senhoriagem, facilitada pelas elevadas taxas de depósitos compulsórios. A existência de depósitos compulsórios remunerados, mesmo sobre depósitos à vista, mostra a ligação do custo dos passivos do Banco Central para as contas públicas, de maneira similar à influência da taxa de juros sobre a dívida pública, seja via dívida indexada, seja através da estrutura a termo da taxa de juros.

\section{REFERÊNCIAS}

Banco Central do Brasil (BACEN). Disponível em: <www.bcb.gov.br>. Acesso em 24/11/08.

Instituto Brasileiro de Geografia e Estatística (IBGE). Disponível em: <www.ibge.gov.br>. Acesso em 24/11/08. 